\title{
Relações Familiares e Dependência Química: Uma Revisão de Literatura
} Family Relationships and Chemical Addiction: A Literature Review

\author{
ANTONIO CLEANO MESQUITA VASCONCELOS ${ }^{1}$ \\ LAMARANOGUEIRAARAÚJO² \\ LAYANE GLEICE MARQUES PORTO² \\ NAYANA NAYLA VASCONCELOS ROCHA ${ }^{3}$ \\ ELIANY NAZARÉ OLIVEIRA ${ }^{4}$ \\ JÔNIA TÍRCIA PARENTE JARDIM ALBUQUERQUE ${ }^{5}$
}

\section{RESUMO}

Objetivo: O artigo objetiva buscar na literatura as relações familiares no contexto da dependência química e assim identificá-las como fator de risco ou de proteção, possível causa ou consequência do uso de drogas. Material e métodos: Trata-se de uma revisão de literatura, onde foi utilizado portal da Biblioteca Virtual em Saúde (BVS), o qual direciona a busca para as bases de dados, durante o mês de dezembro de 2015 . Foram utilizados e cruzados no portal os seguintes descritores: relações familiares e dependência química onde nove artigos foram selecionados para compor a amostra, sendo três da Lilacs, três da BEDENF, e dois da Index Psicologia. Resultados: Aspectos das relações familiares foram identificados como determinantes para a iniciação a uso de drogas: distanciamento dos pais, isolamento, solidão, maus tratos principalmente no público jovem. A dependência química foi identificada como fator preponderante para desestruturação das relações familiares, gerando diversos tipos de transtornos na família, provocando sobrecarga. Conclusão: As relações familiares tanto podem ser causa como consequência do uso indevido de drogas e cabe ao profissional de saúde procurar medidas para sanar esse problema.

\section{DESCRITORES}

Relações Familiares, Dependência Química, Drogas.

\begin{abstract}
Objective: To describe the family relationships in the context of chemical addiction and identify them as risk or protective factors causing, or resulting from, drug abuse. Material and Methods: This was a literature review based on searches carried out in the Virtual Health Library (VHL) during the month of December 2015. The following descriptors and combinations were used: family relationships, and chemical addiction. Eight articles were selected to compose the sample, being three from Lilacs, three from BDENF, and two from Psychology Index. Results: Some aspects of family relationships were identified as determinants for initiation of drug use, such as distancing from parents, isolation, loneliness, and child/young abuse. The articles also showed drug addiction as a major factor for disruption of family relationships, generating various types of disorders and overwhelming the family. Conclusion: Family relationships can be both cause and consequence of chemical addiction. It is up to health professionals to look for measures to control this issue.
\end{abstract}

\section{DESCRIPTORS}

Family Relations. Addiction. Drugs.

1 Monitor do PET Saúde Redes de Atenção 2013/2015. Sobral - CE, Brasil.

2 Acadêmicas do Curso de Enfermagem - Universidade Estadual Vale do Acaraú. Monitoras do PET Saúde Redes de Atenção 2013/2015, Sobral CE, Brasil.

3 Preceptora Mestre do PET Saúde Redes de Atenção 2013/2015, Sobral - CE, Brasil.

4 Docente Doutora do Curso de Enfermagem da Universidade Estadual Vale do Acaraú. Coordenadora do PET Saúde Redes de Atenção 2013/ 2015, Sobral - CE, Brasil.

5 Docente Mestre do Curso de Educação Física da Universidade Estadual Vale do Acaraú. Tutora do PET Saúde Redes de Atenção 2013/2015, Sobral - CE, Brasil. 
$\mathrm{A}$ concepção de abuso e dependência química tem evoluído e sofrido transformações gradativas, decorrentes dos avanços científicos ${ }^{1}$. Atualmente, o abuso de drogas é considerado um problema de saúde pública, pois ocasiona danos de diferentes maneiras ao sujeito, à família e à sociedade. Esses danos podem ser observados por meio de situações, como a repetência na escola, a perda do emprego, a violência, rupturas familiares, crimes, acidentes, entre outros ${ }^{2}$. Ainda, o ser humano relaciona-se de maneira diferente com cada tipo de droga e, dependendo do contexto, essa pode ser inofensiva ou apresentar riscos. Contudo, também, pode assumir padrões de uso disfuncionais, levando a prejuízos biológicos, psicológicos e sociais ${ }^{3}$.

Ao se definir família, consideram-se as múltiplas fun-ções reguladoras dos papéis assumidos por seus membros, contradições de seus comportamentos, afetos, tensões, conflitos presentes no ambiente e que simultaneamente, contribuem para que esse sistema se mantenha dinâmico e em constante transformação, cumprindo seu papel social de gerador e transmissor de crenças, valores e tradições culturais ${ }^{4}$. A família é um sistema aberto, cujos membros se relacio-nam, criam laços emocionais e compartilham suas histórias e experiências. Nessa dinâmica relacional, seus integrantes objetivam a uma estabilidade familiar e convivem com os desafios constantes das mudanças próprias das transições presentes no ciclo vital da família ${ }^{5}$.

A literatura aponta que, no processo de adoecimento do dependente químico, um dos fatores, mas não o único, que o motiva ao uso de dro-gas e às possíveis recaídas tem relação com a inabilidade da família em lidar com o comportamento de seu familiar dependente, necessitando também ela de acolhimento e acompanhamento ${ }^{6}$.

Assim as relações interpessoais inadequadas podem ser preponderantes para o uso indevido de drogas assim como o uso abusivo de drogas pode desgastar as relações interpessoais podendo gerar sobrecarga no familiar do dependente de drogas ${ }^{7}$.

Dessa maneira, este estudo objetivou buscar na literatura as relações familiares no contexto da dependência química e assim identificar tais relações familiares como fator de risco ou de proteção, possível causa ou consequência da do uso indevido de drogas para assim compreender o processo de adoecimento do dependente químico nesse aspecto, a partir disso, o estudo poderá servir de instrumento para subsidiar futuras intervenções.

\section{MATERIALE MÉTODOS}

Este estudo trata-se de uma revisão de literatura, na qual procurou-se a busca por publicações com bases de dados, através do seguinte ponto de partida: o que há na literatura científica sobre relações familiares no contexto da dependência química?

$\mathrm{Na}$ busca, foi utilizado o portal da Biblioteca Virtual em Saúde (BVS), o qual direciona a busca para as bases de dados, durante o mês de dezembro de 2015. Foram utilizados e cruzados no portal os seguintes descritores: relações familiares e dependência química, adjuntos ao operador booleano "and". Tais descritores foram devidamente encontrados nos Descritores em Ciências da Saúde (DeCS). Assim, através da leitura dos resumos e da aplicação dos critérios de exclusão foram selecionados os artigos que constituíram a mostra do estudo.

Foram selecionados apenas artigos científicos que apresentam o texto completo, escrito em língua portuguesa, cujo periódico estivesse indexado à base de dados, livres de recortes temporais e que incluíssem o objetivo da investigação, selecionados a partir de uma leitura criteriosa dos títulos e resumos. $\mathrm{Na}$ pesquisa foram encontrados 102 artigos, entretanto, utilizando os critérios de exclusão acima citados, excluindo-se também alguns artigos que se repetiam, nove artigos que contemplaram o objetivo da pesquisa foram selecionados para compor a amostra, sendo três da Lilacs, três da BEDENF, e dois da Index Psicologia.

Para exposição dos dados foi feito um formulário ${ }^{8}$, onde foram expostas as variáveis: título da pesquisa, periódico, nome dos autores, ano de publicação, objetivos e resultados. Discutimos os resultados utilizando as seguintes categorias: "Relações familiares como determinante do uso indevido de drogas" e "Desgaste nas relações familiares como consequência do uso indevido de drogas".

\section{RESULTADOS E DISCUSSÃO}

O quadro abaixo contém informações sobre os nove artigos encontrados pertinentes ao assunto, sendo apresentado título do artigo, nome do periódico, nome dos autores, ano de publicação, objetivos do estudo e resultados.

Durante a leitura dos artigos foram encontradas duas categorias as quais são descritas abaixo como resultado da revisão sendo elas "Relações familiares como determinante do uso indevido de drogas" e "Desgaste nas relações familiares como consequência do uso indevido de drogas". 


\begin{tabular}{|c|c|c|c|}
\hline $\begin{array}{c}\text { Título do Artigo/ Nome do } \\
\text { Periódico }\end{array}$ & $\begin{array}{l}\text { Autores/ ano da } \\
\text { publicação }\end{array}$ & Objetivos do Estudo & Resultados \\
\hline $\begin{array}{l}\text { 1. As relações interpessoais } \\
\text { e o consumo de drogas por } \\
\text { adolescentes I } r \text { Rev. } \\
\text { Eletrônica Saúde } \\
\text { Álcool Drog. }\end{array}$ & $\begin{array}{l}\text { Dietz; Santos; } \\
\text { Hildebrandt; } \\
\text { Leite/ } 2001{ }^{9} \text {. }\end{array}$ & $\begin{array}{l}\text { Conhecer, sob a ótica de } \\
\text { adolescentes dependentes } \\
\text { químicos, os motivos que os } \\
\text { levaram a iniciar o consumo de } \\
\text { substâncias psicoativas. }\end{array}$ & $\begin{array}{l}\text { Resultados apontaram as relações do } \\
\text { adolescente com a familia, amigos, escola } \\
\text { e comunidades como fatores } \\
\text { determinantes para o início ou não do uso } \\
\text { de drogas. }\end{array}$ \\
\hline $\begin{array}{l}\text { 2. Aspectos da dinâmica da } \\
\text { família com dependência } \\
\text { química/ Estudos de } \\
\text { Psicologia. }\end{array}$ & $\begin{array}{l}\text { Paz; Colossi/ } \\
2013^{10} .\end{array}$ & $\begin{array}{l}\text { Compreender a dinâmica da } \\
\text { família do dependente químico. }\end{array}$ & $\begin{array}{l}\text { Necessidade de compreensão da } \\
\text { dependência química, que pode ser } \\
\text { influenciado pela dinâmica familiar } \\
\text { reforçando aspectos de seu } \\
\text { funcionamento para a manutenção do } \\
\text { sintoma. }\end{array}$ \\
\hline $\begin{array}{l}\text { 3. Aspectos familiares de } \\
\text { meninas adolescentes } \\
\text { dependentes de álcool e } \\
\text { drogas/ Rev Psiquiatria } \\
\text { Clínica. }\end{array}$ & $\begin{array}{l}\text { Guimarães; Hochgraf; } \\
\text { Brasiliano; } \\
\text { Ingberman/ } \\
200911\end{array}$ & $\begin{array}{l}\text { Revisão da literatura sobre o tema } \\
\text { familia de adolescentes } \\
\text { abusadoras e/ou dependentes de } \\
\text { substâncias psicoativas, a fim de } \\
\text { levantar quais dados a literatura já } \\
\text { dispõe sobre esse assunto. }\end{array}$ & $\begin{array}{l}\text { As famílias em sua maioria possuem } \\
\text { características disfuncionais como laços } \\
\text { familiares conflitivos, pouca proximidade } \\
\text { entre os membros, falta de uma hierarquia } \\
\text { bem definida e pais que não dão exemplo } \\
\text { positivo quanto ao uso de drogas. }\end{array}$ \\
\hline $\begin{array}{l}\text { 4. } 0 \text { cotidiano das relações } \\
\text { familiares com indivíduo } \\
\text { dependente químico/ } \\
\text { Cogitare Enfermagem. }\end{array}$ & $\begin{array}{l}\text { Soccol; Terra; Ribeiro; } \\
\text { Teixeira; Siqueira; } \\
\text { Souza; Mostardeiro/ } \\
2014{ }^{12} \text {. }\end{array}$ & $\begin{array}{l}\text { Conhecer } 0 \text { cotidiano das } \\
\text { relações familiares com um } \\
\text { individuo dependente químico. }\end{array}$ & $\begin{array}{l}\text { Evidencia-se que a dependência química } \\
\text { ocasiona estreitamento dos laços de } \\
\text { confiança nas relações intrafamiliares e } \\
\text { pode causar } 0 \text { adoecimento das familias. }\end{array}$ \\
\hline $\begin{array}{l}\text { 5. O papel das relações } \\
\text { familiares na iniciação ao } \\
\text { uso de drogas de abuso por } \\
\text { jovens institucionalizados / } \\
\text { Revista Escola de } \\
\text { Enfermagem USP. }\end{array}$ & $\begin{array}{l}\text { Bernardy; Oliveira/ } \\
2010 \text { 13. }\end{array}$ & $\begin{array}{l}\text { Analisar o papel das relações } \\
\text { familiares na iniciação ao uso de } \\
\text { drogas e abuso por parte de } \\
\text { jovens cumprindo medidas sócio- } \\
\text { educativas. }\end{array}$ & $\begin{array}{l}\text { Sinais de negligência e abandono, } \\
\text { agressões fisicas e falta de diálogo } \\
\text { familiar e, principalmente, a cultura do uso } \\
\text { de drogas no ambiente familiar } \\
\text { determinaram a iniciação ao uso de } \\
\text { drogas de abuso. }\end{array}$ \\
\hline $\begin{array}{l}\text { 6. Relações entre contexto } \\
\text { familiar e uso de drogas em } \\
\text { adolescentes de ensino } \\
\text { médio/ } \\
\text { Rev. } \\
\text { Enfermagem. }\end{array}$ & $\begin{array}{l}\text { Garcia; Pillon; Santos/ } \\
2011^{14} \text {. }\end{array}$ & $\begin{array}{l}\text { Descrever características do } \\
\text { contexto familiar de adolescentes } \\
\text { de ensino secundário e suas } \\
\text { relações com o uso de } \\
\text { substâncias psicoativas. }\end{array}$ & $\begin{array}{l}\text { Os resultados mostraram que os } \\
\text { adolescentes tinham boas relações com a } \\
\text { mãe, porém não mostravam confiança na } \\
\text { figura materna. Apresentavam } \\
\text { antecedentes usuários de substâncias, } \\
\text { sendo normalmente o pai. }\end{array}$ \\
\hline $\begin{array}{l}\text { 7. Representações sociais } \\
\text { do uso e abuso de drogas } \\
\text { entre familiares de usuários/ } \\
\text { Rev. Psicologia em Estudo. }\end{array}$ & 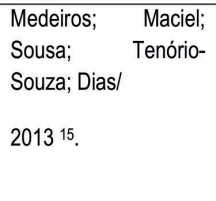 & 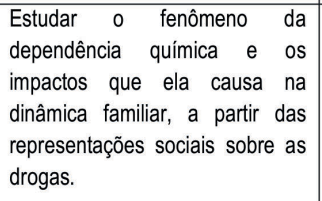 & $\begin{array}{l}\text { Os resultados indicaram que esses } \\
\text { familiares representaram as drogas como } \\
\text { algo nocivo, que prejudica as relações } \\
\text { familiares, sendo responsáveis por } \\
\text { conflitos e desarmonia na família. }\end{array}$ \\
\hline $\begin{array}{l}\text { 8. Uso de drogas ilícitas e } \\
\text { perspectivas críticas de } \\
\text { familiares e pessoas } \\
\text { Próximas na cidade do Rio } \\
\text { de Janeiro - zona norte, } \\
\text { Brasil/ Rev latino-am } \\
\text { enfermagem }\end{array}$ & $\begin{array}{l}\text { Loyola; Brands; Adlaf; } \\
\text { Giesbrecht; Simich; } \\
\text { Wright/ } 2009{ }^{16} \text {. }\end{array}$ & $\begin{array}{l}\text { Buscou saber como familiares de } \\
\text { usuários de drogas ilícitas } \\
\text { descrevem fatores de proteção e } \\
\text { de risco, iniciativas de prevenção, } \\
\text { serviços de tratamento, leis e } \\
\text { políticas sobre as drogas ilícitas. }\end{array}$ & $\begin{array}{l}\text { A dinâmica Familiar que mais expõe à } \\
\text { droga é a negligência e a que mais } \\
\text { protege é a relação de apoio com os pais. } \\
\text { A política, a polícia e o sistema criminal } \\
\text { não têm diminuído o consumo e não } \\
\text { protegem o usuário. }\end{array}$ \\
\hline $\begin{array}{l}\text { 9. Uso de substâncias na } \\
\text { adolescência } \\
\text { e problemas familiares/ } \\
\text { Cad. Saúde Pública. }\end{array}$ & $\begin{array}{l}\text { Malbergier; Cardoso; } \\
\text { Amaral/ } \\
2012^{17} \text {. }\end{array}$ & $\begin{array}{l}\text { Avaliar a associação entre } 0 \\
\text { consumo de substâncias e } \\
\text { problemas em } 50 \text { escolas públicas } \\
\text { no Estado de São Paulo, Brasil, } \\
\text { em } 2007 \text {. }\end{array}$ & $\begin{array}{l}\text { Os resultados apontam para a } \\
\text { importância de se ficar atento ao consumo } \\
\text { de álcool e tabaco entre os adolescentes, } \\
\text { já que o relato do consumo das duas } \\
\text { substâncias esteve associado a prejuízos } \\
\text { familiares significativos. }\end{array}$ \\
\hline
\end{tabular}




\section{Relações familiares como determinante do uso indevido de drogas}

Apesar da pesquisa não enfocar nenhuma faixa etária específica, essa seção já trata com maior ênfase das relações familiares do público jovem, isso se dá por essa etapa constituir em uma fase crucial quanto ao uso ou não uso de drogas. De modo geral os artigos trazem a ideia de que as relações familiares são determinantes para o uso indevido de drogas, sendo tanto fator de risco quanto de proteção para o uso indevido de drogas.

Mesmo constituindo uma família aparentemente completa, ou seja, sem ausência de algum familiar parental não exclui os riscos de relações desgastadas, propícias ao uso de drogas por falta de maior proximidade intrafamiliar, falta de confiança entre si, dentre outros fatores ${ }^{11,14}$.

A falta de interação entre familiares, de diálogos também aparece aqui como fator de risco para o uso de drogas. O que distancia o adolescente dos adultos, aí pode desencadear a base das relações sociais serem transferidas para os ciclos de amizades. Essa situação já acarretará outra que é a influência dos ciclos de amizades como fator de risco ao uso de drogas, pois na adolescência costuma ser uma fase onde há a predominância do anseio pelas descobertas, busca por novas sensações e emoções, como também a afirmação social, a busca pela independência. Tais relações naturalmente afastam o jovem da família, e se essa não tiver próxima, será um problema muito maior e difícil de solucionar ${ }^{9,13}$.

Relações familiares conflituosas aparecem aqui como determinantes para o uso de drogas, existindo vários elementos do cotidiano das relações familiares e hábitos dos mesmos que podem ser preponderantes a iniciação ao uso de drogas. Podemos citar o clima conflituoso dentro de casa, o que inclui briga entre os pais, separação do casal, relação conflituosa com os irmãos. Tudo isso gera uma realidade incipiente a uma maturação saudável, composta por projeções adequadas de amadurecimento, o que pode certamente ser uma possível causa do uso de drogas ${ }^{9}$.

Nesse caso, há também o fato dos adultos, que deveriam ser as figuras responsáveis por servirem de base, as referências e lideranças no ambiente familiar, no entanto, quando esse ambiente se encontra desestruturado, repleto de desarmonias, conflitos e condutas inadequadas por parte dos responsáveis, se torna um fator de risco ${ }^{9,13}$. Fatores como curiosidade, uso de drogas por conta da solidão, circunstâncias familiares, negligência, rejeição constituem fortíssimos determinantes para o uso de drogas ${ }^{16}$.

Os conflitos familiares envolvendo diretamente quanto indiretamente aparecem também como um possível determinante para o uso de drogas. A presença de violência nas famílias de adolescentes, a presença de discussões, incidência de maus-tratos verbais e físicos, bem como abuso sexual, o que indica que a violência intrafamiliar pode ser fator de risco para o uso de substâncias pelos adolescentes deste estudo, sobretudo quando combinada com o uso de drogas lícitas e ilícitas para enfrentarem problemas familiares 13,14

\section{Desgaste nas relações familiares como consequência do uso indevido de drogas}

Após a análise de cada artigo observou-se que alguns artigos resultaram basicamente na sobrecarga do familiar frente à problemática do filho dependente químico. A aflição propagada pelo familiar advém do desempenho inconstante do dependente químico, originando esgotamento em sua convivência com o mesmo e origina sentimentos de incerteza e de fraqueza. Também foi visto que o problema com a dependência química pode causar sentimentos de vergonha. Logo, pode-se afirmar que a dependência química gera desordem nas relações familiares, fazendo com que a família experimente crises e desordens, estreitando laços familiares.

A entrada das drogas causa na vida dos familiares envolvidos com o dependente, como a ruptura do convívio pacífico entre os membros da família e as dores de fragilidade, abandono e insatisfação quanto ao tratamento da doença. Além disso, ocorre agravamento de conflitos já existentes, acentuando ainda mais as dificuldades dos familiares em lidar com a dependência química remetendo-os à codependência, seria exatamente esse aspecto o que interfere na vida dos familiares do dependente, o qual se traduz num imenso sofrimento psíquico ${ }^{15}$.

Sabe-se que diante das dificuldades de conviver com uma pessoa com sofrimento psíquico, (dependente de álcool e outras drogas), as famílias enfrentam as dificuldades de continuarem tocando as atividades normais; a vida cotidiana na casa e cuidar para que o usuário, uma vez em casa, participe do Centro de Atenção Psicossocial (CAPS), tome os medicamentos e não frequente espaços que os incitem a usar outra vez as drogas, portanto, as famílias necessitam sim, ser gradativamente trabalhadas em suas relações, a fim de encontrar um estado de equilíbrio adequado ${ }^{7}$.

Afirma a família não estar preparada para suportar tal grau de desorganização provocado pelas condições de incerteza mesmo que só um membro da família seja dependente químico, todos precisam de 
tratamento, pois a família adoece junto. E falando de necessidade de tratamentos, 2 artigos trazem a responsabilização de cuidados a famílias atingidas pela consequência do dependente químico. Evidenciando a importância do atendimento psicológico às famílias de dependentes químicos nos serviços públicos de atenção à saúde, cuidar, não apenas do paciente dependente químico que está adoecido, mas do sistema familiar do qual faz parte ${ }^{12}$. Os artigos trazem como conclusões a necessidade de ressaltar a proteção e suporte das famílias como alvo das políticas públicas ${ }^{10,16}$. Destacase a relevância da família ser acolhida e tratada, visando restaurar os vínculos familiares, estabelecer os limites fragilizados e reorganizar os papéis familiares.

Com relação a sobrecarga familiar do dependente de psicoativos, dos nove artigos encontrados quatro deles não identificaram/evidenciaram diretamente o desgaste familiar pós uso de drogas pelos filhos mas apontam indicadores de risco, uso de substância e a manutenção destas além do aspecto problemático entre a família nuclear e do relacionamento de usuários com cada parente como influência. Os artigos também falam de comportamento e como reduzir o consumo de drogas por adolescentes. As relações estabelecidas pelos adolescentes com a família, amigos, escola, comunidade são fatores determinantes para o desenvolvimento e a manutenção da dependência química. Os adolescentes que usaram drogas ilícitas relataram ter mais problemas familiares. Porém não foi apontado os problemas nem desgastes especificamente ${ }^{17}$.

\section{CONCLUSÕES}

Através dessa revisão, observamos que as relações familiares são de fato fatores determinantes do uso indevido de drogas através de aspectos como falta de diálogo na família, desprezo familiar, falta de afeto, substituição da família por ciclos de amizades inseguros, conflitos, violência moral e física. Em contrapartida, relações familiares positivas podem ser fatores de proteção ao uso indevido de drogas. Com relação ao outro aspecto analisado, a dependência química por sua vez abala e desestrutura as relações familiares, gerando desconforto, conflitos na família, enfraquecendo as relações e promovendo sobrecarga familiar em maior ou menor escala.

Desse modo, podemos compreender as relações familiares como um fator diretamente interligado à dependência química, pois tanto podem ser causadoras do uso indevido de substâncias psicoativas, como podem ser consequência da dependência química através do desgaste das mesmas em função de um uso problemático. Assim, em se tratando do cuidado, as relações familiares devem ser compreendidas em cada caso para que haja uma abordagem integral, focada no indivíduo e nas relações do mesmo com seu contexto, caso contrário, se as relações familiares forem desconsideradas, a abordagem se tornará limitada, desconsiderando uma parte importantíssima desse processo.

\section{REFERÊNCIAS}

1. Matos MTS, Pinto JM, Jorge MSB. Grupo de orientação familiar em dependência química: uma avaliação sob a percepção dos familiares participantes. Rev. Baiana Saúde Pública. 2008; 32(1): 58-71.

2. Schenker M. Valores familiares e uso abusivo de drogas. Rio de Janeiro: Fiocruz; 2008.

3. Duarte CE, Morihisa RS. Experimentação, uso, abuso e dependência de drogas. In: Secretaria Nacional de Políticas sobre Drogas. Prevenção do uso de álcool e outras drogas no ambiente de trabalho: conhecer para ajudar. 3a ed. Brasília: Ministério da Justiça; 2012.

4. Payá R, Figlie NB. Abordagem Familiar em Dependência Química. In: Figlie NB, Bordin S, Laranjeira R, organizadores. Acon-selhamento em Dependência Química. 2.ed. São Paulo: Roca; 2010.

5. Minuchin P. Trabalhando com famílias pobres. Porto Alegre: Artes Médicas Sul; 1999.

6. Ortha APS, Moréb CLOO. Funcionamento de famílias com membros dependentes de substâncias psicoativas. Psicol. Argum. 2008; 26(55): 293-303.

7. Melo, PF; Paulo, MAL. A importância da família na recuperação do usuário de álcool e outras drogas. Saúde Coletiva em Debate. 2012; 2(1): 41-51.

8. Oliveira EN, Eloia SMC, Lima D S, Eloia SC, Felix TA Vasconcelos MIO. A família no cuidado à pessoa com transtorno mental: uma revisão integrativa. Rev. Tendên. Da Enferm. Profis., 2014; 6(1):1196-1202.

9. Dietz G, Santos CG; Hildebrandt $\mathbf{L} \boldsymbol{M}$; Leite MT. As relações interpessoais e o consumo de drogas por adolescentes. Rev. Eletrônica Saúde Mental Álcool Drog. 2011;7(2):85-91.

10. Paz FM, Colossi PM. Aspectos da dinâmica da família com dependência química. Estudos de Psicologia. 2013; 18(4): 551-558.

11. Guimarães ABP, Hochgraf PB, Brasiliano S, Ingberman YK. Aspectos familiares de meninas adolescentes dependentes de álcool e drogas. Rev. Psiq. Clín. 2009; 36(2): 69-74.

12. Soccol KLS, Terra MG, Ribeiro DB, Teixeira JKS, Siqueira DF, Mostardeiro SCTS. O cotidiano das relações familiares com indivíduo dependente químico. Cogitare Enferm. 2014; 19(1):116-22.

13. Bernardy CCF, Oliveira MLF. O papel das relações familiares na iniciação ao uso de drogas de abuso por jovens institucionalizados. Rev. Esc. de Enf. USP. 2010; 44(1): 11-7. 
14. Garcia JJ; Pillon SC; Santos MA. Relações entre contexto familiar e uso de drogas em adolescentes de ensino médio Rev. Latino-Am. Enfermagem 2011; 19(esp.): 75361.

15. Medeiros KT; Maciel SC; Sousa PF; Tenório-Souza; Dias, CCV. Representações sociais do uso e abuso de drogas entre familiares de usuários. Psicologia em Estudo. 2013; 18(2): 269-279.

16. Loyola, C. M. D. Uso de drogas ilícitas e perspectivas críticas de familiares e pessoas próximas na cidade do Rio de Janeiro - zona norte, brasil. rev latino-am enfermagem. 2009; 17(esp.):817-23.
17. Malbergier A; Cardoso LRD; Amaral RA. Uso de substâncias na adolescência e problemas familiares Cad. Saúde Pública, Rio de Janeiro, 2012; 28(4):678688.

Correspondência

Antonio Cleano Mesquita Vasconcelos

Endereço: Rua Diogo Alves de Loiola, 272 - Alto Alegre CEP: $62115-000$

Forquilha - Ceará - Brasil

E-mail: cleano.vasconcelos@hotmail.com 